\title{
EDITORIAL
}

\section{Embarazo en adolescentes}

Viene a mi memoria el curso de Ginecología Infanto Juvenil, realizado en Cúcuta del 9 al 11 de octubre de 1982, donde tuve una ponencia sobre embarazo en adolescentes y señalaba en esa reunión que el embarazo en esta etapa de la vida en la que se realiza la transición de un niño a un adulto, es la menos indicada para asumir la responsabilidad que implica engendrar un hijo, criarlo y formarlo, para que en el futuro sea un adulto útil para su familia y la sociedad.

El embarazo en esta época de la vida debe ser considerado de alto riesgo por sus implicaciones médicas y sociales, plenamente establecidas en los diferentes estudios que sobre el tema se han realizado tanto en Colombia como en el exterior, como lo demostró el estudio cooperativo de Embarazo en adolescentes realizado en once instituciones colombianas publicado en la Revista Colombiana de Obstetricia y Ginecología y referido por el doctor Alvaro Monterrosa en el estudio publicado en el presente número de la revista. Sea el momento para recordar que riesgo en medicina es la presencia de un factor o factores que hacen a una persona o a un grupo de individuos más susceptibles de sufrir un daño que el resto de la población general.

Se insistía en esa época en que el embarazo en adolescentes estaba en aumento y que los padres, maestros, personal de salud y la sociedad en general, debíamos hacer algo pronto a fin de evitarlo durante este período del desarrollo del ser humano.

Sin embargo, lejos de estar controlado o en disminución, el embarazo en adolescentes en el mundo y en nuestro medio sigue en aumento, como lo demuestra el excelente estudio realizado por el doctor Alvaro Monterrosa en el Hospital Maternidad "Rafael Calvo" de Cartagena.

Son varios los factores que influyen y han influido en el aumento del embarazo en esta época de la vida como son: el inicio temprano de las relaciones sexuales heterosexuales, maduración sexual temprana, mayor libertad de horario, mayor facilidad de encuentros íntimos, no uso de anticoncepción preventiva por ignorancia o por inaccesibilidad a los mismos, o falla del método anticonceptivo cuando los usan por utilizar aquellos de baja seguridad o con alto riesgo de falla como son todos los métodos naturales. En nuestro medio han influido además de los anteriormente mencionados, el concepto que persistió por muchos años, de que el problema del embarazo en adolescentes era propio de países desarrollados de Europa y Estados Unidos y la persecución de actividades sexuales normales de los adolescentes, como la masturbación que no es ni pecado ni aberración ni mucho menos antinatural, sino parte del desarrollo psicosexual normal del ser humano y el homosexualismo transitorio del adolescente que desaparece con la maduración y el establecimiento de las relaciones heterosexuales del adulto.

Estas actitudes de padres y maestros empujan al adolescente a relaciones sexuales heterosexuales, que sin el uso de la anticoncepción preventiva dan como resultado un embarazo a una edad que en su inmensa mayoría es indeseado, con sólo tres alternativas para quien lo presenta: tener el hijo y conservarlo como madre soltera o en unión forzosa 
con las consecuencias para un hijo indeseado a saber: infanticidio, homicidio inconsciente, niño golpeado o maltratado, abandono, rechazo y aceptación tardía. No tener el hijo y someterse al aborto provocado, siempre ilegal en Colombia. O ceder el hijo por medio de la adopción le gal o ilegal. Cualquiera de las tres alternativas traen para la joven adolescente trastornos psicológicos, el principal la depresión, que la puede empujar al alcoholismo, la drogadicción o el suicidio.

Como alguien muy bien decía, el embarazo es asunto de adultos, pero esperar que con sólo la educación el adolescente va a posponer sus relaciones heterosexuales hasta ser adulto es una utopía. Los adolescentes hoy son cada vez sexualmente más activos a más temprana edad, por lo tanto se hace absolutamente necesario prevenir el embarazo en los adolescentes con la utilización de métodos anticonceptivos modernos y efectivos.

Desafortunadamente, los estudios han demostrado que pocos adolescentes usan métodos anticonceptivos en su primera relación sexual, especialmente sin son solteros. Generalmente transcurre en promedio un año entre la primera relación sexual de una mujer y la primera vez que usa un método anticonceptivo; muchos embarazos ocurren dentro del año en que inician o realizan su primera relación sexual, y la mayoría no son previstos.

En abril de 1998, en Nueva York, el doctor Nafis Sadik durante una mesa redonda de expertos en salud sexual y reproductiva de los adolescentes, un área del programa de acción de la Conferencia Internacional sobre Población y Desarrollo (CIPD), en su discurso de apertura comentó: "aunque los adolescentes son cada vez sexualmente más activos, la provisión de información y servicios de salud reproductiva sigue siendo un asunto muy espinoso, y las actitudes de los padres y la sociedad suelen ser un importante obstáculo en esta área".

Finalmente y siendo reiterativo, quiero dejar un mensaje para nosotros como educadores médicos y padres: no nos sigamos engañando, nuestros adolescentes, son probablemente en su mayoría, sexualmente activos; eduquémoslos y permitámosles conocer y acceder a la prevención del embarazo en la adolescencia, que no es otra que el uso adecuado de los modernos y efectivos métodos anticonceptivos.

DOCTOR GERMAN URIZA GUTIERREZ Profesor Titular. Pontificia Universidad Javeriana. 